\title{
Sánchez, R. (2009). Psicología y dependencia. De la ley a la intervención psicosocial. Salamanca: Universidad Pontificia de Salamanca.
}

\section{Sánchez, R. (2009). Psychology and dependence. From law to psychosocial intervention. Salamanca: Universidad Pontificia de Salamanca.}

\author{
Esperanza Bausela \\ Universidad Nacional de Educación a Distancia
}

La ley de Promoción de la Autonomía Personal y Atención a las Personas en Situación de Dependencia, conocida más popularmente como Ley de Dependencia, es el eje en torno al que gira el presente manual. Tal y como se señala en el B.O.E. núm. 299, de 15 diciembre 2006 tiene por objeto regular las condiciones básicas que garanticen la igualdad en el ejercicio del derecho subjetivo de ciudadanía a la promoción de la autonomía personal y atención a las personas en situación de dependencia, en los términos establecidos en las leyes, mediante la creación de un Sistema para la Autonomía y Atención a la Dependencia, con la colaboración y participación de todas las Administraciones Públicas y la garantía por la Administración General del Estado de un contenido mínimo común de derechos para todos los ciudadanos en cualquier parte del territorio del Estado español.

La dependencia es, según Pérez y Yanguas (1998), un fenómeno complejo, que presenta diversas dimensiones, causas y funciones y que difícilmente es reducible a una única configuración y que puede ser definida.

La persona dependiente ha sido definida en el Libro Blanco de la Dependencia (2004) como aquélla que no puede realizar, sin ayuda, alguna de las actividades básicas de la vida diaria relacionadas con el cuidado personal, la movilidad dentro del hogar o las funciones mentales básicas. Siguiendo a Pérez y Yanguas (1998), la dependencia es definida como "la necesidad del individuo de ser ayudado o apoyado para ajustarse a su medio e interaccionar con él puede ser analizado desde diversos puntos de vista. Así desde una aproximación funcional, se puede definir la dependencia a partir del ajuste de los individuos a las demandas de su medio físico y social". La dependencia puede ser económica, física, social o mental, cuando el individuo pierde su capacidad para resolver sus problemas y tomar decisiones propias. Es en esta última en la que se centra el presente manual.

En Psicología y dependencia. De la ley a la intervención psicosocial se analiza el papel y el posible campo de actuación de la Psicología que permitirá el desarrollo práctico y aplicado de esta ley de apoyo e intervención psicosocial. Este análisis se une a las conclusiones del debate - Ley de Dependencia desarrollado en los desayunos de INFOCOP, quienes concluyen, una vez que la Ley ha sido definitivamente aprobada, que la inestimable labor profesional e investigadora que los psicólogos y psicólogas están realizando en el campo de la discapacidad, contrasta con la escasa presencia y reconocimiento de la Psicología y los psicólogos en la Ley de Dependencia.

A nivel psicológico se interviene con poblaciones dependientes con un mejor bagaje de técnicas, de habilidades y conocimientos para coordinar y articular actividades dirigidas a esta población, que incluye en un alto porcentaje a personas mayores de 65 años, personas con discapacidad y enfermos crónicos. Así en la propia ley se recoge "A esta realidad, derivada del envejecimiento, debe añadirse la dependencia por razones de enfermedad y otras cau- 
sas de discapacidad o limitación, que se ha incrementado en los últimos años por los cambios producidos en las tasas de supervivencia de determinadas enfermedades crónicas y alteraciones congénitas y, también, por las consecuencias derivadas de los índices de siniestralidad vial y laboral".

A continuación se presentan los contenidos correspondientes a los cinco bloques en torno a los cuales se organizan los dieciséis capítulos: Bloque I: Aclarando términos. La ley de dependencia: (i) Discapacidad y dependencia. (ii) El desarrollo de la ley de promoción de la autonomía personal y la atención a las personas en situación de dependencia. Bloque II: Aspectos Psicológicos en la dependencia: (iii) Autonomía y dignicidad en la condición dependiente. Del duelo a la reconstrucción. Aspectos deontológico y prácticos. (iv) Trastornos mentales y dependencia. (v) El anciano terminal: la dependencia como expresión última de la vida. Bloque III: Aspectos familiares en la dependencia: (vi) Familia y dependencia: una mirada distinta, una respuesta diferente. (vii) Efectos en los niños de madres drogodependientes en el embarazo. (viii) Estimulación temprana: intervención en niños de cero a tres años. Bloque IV: Intervención en casos de dependencia: (ix) Intervención pscológica integral en vejez. (x) Daño cerebral y dependencia. (xi) Autodeterminación y personas con discapacidad intelectual. Apostando por un ocio inclusivo y autodeterminado. (xii) Intervención logopédica en situaciones de dependencia: un caso de demencia semántica. (xiii)
Principales retos en la prevención de la dependencia en personas mayores. (xiv) Sociedad rural y envejecimiento en la provincia de Salamanca. Bloque $V$ : Los centros y asociaciones para personas dependientes: (xv) Centro de referencia estatal de atención a personas con enfermedad de Alzheimer y otras dependencias. (xvi) ¿Qué es Insolamis?¿Cómo nace Insolamis?

Consideramos que el presente documento, a través de sus diferentes capítulos, ofrece una panorámica completa de la actuación profesional del psicólogo y del psicopedagogo en el marco de actuación que se inserta la llamada Ley de Dependencia, cuyo principal objetivo es definir las necesidades de ayudas y regular la obtención de los recursos necesarios apoyándose en los principios de universalidad, equidad y accesibilidad.

\section{Referencias}

Ministerio de Trabajo y Asuntos Sociales, Imserso (2004). La Atención a las personas en situación de dependencia en España. Libro Blanco. Madrid: MTAS, IMSERSO. Disponible en: http://www.mtas.es//inicioas_ dependencia/depen. htm

Pérez, M. y Yanguas, J.J. (1998). Dependencia, personas mayores y familias. De los enunciados a las intervenciones. Anales de Psicología, 14 (1), 95104. 